\title{
Necessary and Sufficient Conditions for Liquidity Management
}

\author{
José Antonio de França ${ }^{1} \&$ Wilfredo Sosa Sandoval ${ }^{2}$ \\ ${ }^{1} \mathrm{PhD}$ in Accountancy, University of Brasilia (UnB), Brazil \\ ${ }^{2} \mathrm{PhD}$ in Mathematics, Catholic University of Brasilia (UCB), Brazil \\ Correspondence: José Antonio de França, PhD in Accountancy, University of Brasilia (UnB), Brazil. E-mail: \\ franca@itecon.com.br
}

Received: February 242019

Accepted: March 22, 2019

Online Published: April 15, 2019

doi:10.5539/ijef.v11n5p85

URL: https://doi.org/10.5539/ijef.v11n5p85

\begin{abstract}
Liquidity as a measure of payment capacity must incorporate the attributes of efficiency, sustainability and synergy. Traditionally, liquidity is measured by financial indicators, centered in the current ratio (CR) as an indicator of nominal payment capacity. However, this indicator generates a gap in the liquidity assessment because it does not measure financial efficiency nor liquidity sustainability. This research paper proposes an indicator that combines nominal capacity with effective payment capacity that indicates the liquidity sustainability and financial efficient status, addressing a gap in the literature concerning liquidity management, and revealing the existence of financial synergy. In order to test this proposition, data from financial statements of 37 manufacturing firms from 2000 to 2015 were used, via parametric and nonparametric methods. In the analysis showed here, financial efficiency ratio (FER) and the liquidity sustainability ratio (LSR) were used to assess financial efficiency and sustainable liquidity. Robust empirical evidence was found showing that the main status of the firms' liquidity is weakly sustainable and therefore does not produce financial synergy. The results suggest that the combination of financial efficiency and nominal liquidity is a robust technique to indicate the firm's liquidity status.
\end{abstract}

Keywords: liquidity sustainability coefficient, necessary and sufficient conditions, financial efficiency ratio, financial synergy

\section{Introduction}

Liquidity, as the result of the combination of basic sustainability factors, what the literature calls financial synergy, is sustained by positive net cash flows resulting from internal financing costs lower than external financing costs, as well as from operational performance and asset productivity (Copeland, Weston, \& Shastri, 2005, pp. 762-763). However, the literature on financial synergy focuses mainly on calculating and analyzing the ratio between financial quantities that represent assets and liabilities in the standardized financial statements of firms, neglecting, in particular, the contribution of the temporal physical quantities, which are essential to the assessment of cash flows. These temporal physical quantities are represented by the financial cycle, which, when combined with the traditional liquidity index, can reduce asymmetries and positively improve the firm's financial planning.

Aiming at reducing asymmetries, this article discusses liquidity management efficiency within the financial sustainability context, combining financial quantities with temporal physical quantities, which is expected to obtain a reliable indicator of liquidity sustainability able to connect information on nominal capacity of payment with information on sustainable liquidity, signaling the existence of financial synergy. This proposed indicator is relevant to enrich the literature, because it shows the minimum point of sustainable liquidity and completes the studies initiated by Gentry, Vaidyanathan, and Lee (1990); Soenen (1993); Moss and Stine (1993); Stewart (1995), Farris II and Hutchison (2002); Lancaster, Stevens, and Jennings (1998);Gitman (2002, p. 112) among others, who preliminarily analyzed the subject.

Traditionally, liquidity is a financial metrics used to assess a firm's performance through financial indicators produced from pieces of information generated by accounting, with an emphasis on the current ratio (CR), with the purpose of determining the firm's nominal payment capacity in a given period of time. CR results from the relationship between the firm's current assets and liabilities, in a context of positive working capital (PWC). However, liquidity assessment does not ensure financial efficiency nor liquidity sustainability because it does not 
interact with activity indicators to synchronize the timing of cash inflows and outflows, as Richards and Laughlin (1980) have already shown.

Research studies published in the last decades show, in a general sense, that firms need to be sustainable in order to continue operating successfully. In this context, being sustainable means that a firm must be able to maintain enough cash flow to guarantee liquidity, must use natural resources at a rate lower than the natural production rate, and must refrain from producing emissions of materials that accumulate in the environment at a rate beyond the ecosystem's natural capacity to absorb or assimilate them. Moreover, it means that a firm must not get involved in activities that degrades the ecosystem's services, must respect workers' rights, must not make use of slave or child work, must practice free trade and must not cease to present consistent above-the-average return to its shareholders. This is argued by Dyllick and Hockerts (2002); Koellner, Weber, Fenchel, and Scholz (2005); Christofi, Christofi, and Sisaye (2012); Belaggio (2012); McDonagh (2002); Fair Trade Federation (1999). Also, the sum of these factors cannot be lower than the whole, as approached by Pope, Annandale and Morrison-Saunders (2004).

The commitment to ecological and social aspects is relevant for the business sustainability, but in this article, the discussion in centered on the microeconomic quantities totaled in the CA and the CL of the standardized financial statements of the firms. Hence, the focus of interest and motivation of this article seeks to fill a gap identified in the area's literature regarding the lack of interaction between nominal payment capacity, measured by the $\mathrm{CR}$, and activity indicators (operating cycle (OC) and financial cycle (FC)). This is observed when combining the timing of a firm's cash inflows and outflows in order to signal the firm's financial efficiency status, as discussed by Richards and Laughlin (1980) and by Lancaster, Stevens, and Jennings (1998).

Based on these circumstances, this research study's motivation concerns the proposition of an indicator that combines the firm's nominal capacity with effective payment capacity to show the financial efficiency status and liquidity sustainability. In order to test empirically the effectiveness of this proposed indicator, we have used accounting variables from financial statements of a sample of firms listed in BM\&FBOVESPA, from 2010 to 2015, within the Brazilian manufacturing industry. The means used to answer the question proposed are (a) to calculate the nominal payment capacity measured by the current ratio by using the standard financial statements of each firm; (b) to acquire a scale, measured in days, of activity indicators and combine them with the current ratio (CR) in order to obtain effective payment capacity. These objectives give grounds to the research's proposition that will contribute to the literature of financial analysis by providing a consistent methodology, and will even strengthen the relationship between scholars and market professionals, besides assessing financial synergy existence.

Because the current ratio (CR) is a measure of static evaluation and activities indicators have dynamic characteristics (Lancaster; Stevens; Jenning, 1999), in this article we present the financial efficiency ratio (FER) as a necessary and sufficient condition to assess whether a company is financially efficient. We also combine the FER with the current ratio to produce a liquidity sustainability ratio (LSR) that shows the firm's effective payment capacity and financial solvency. The combined and simultaneous use of these two ratios mitigates and fills the gap identified in the area's literature regarding liquidity management.

By reducing the deficiency of liquidity analysis, existent in the traditional literature, this research study assumes robust results to be confirmed by empirical tests with the support of adequate assessment methodology, using positivist and deterministic methods. These results render significant contribution to the literature in the academic and professional market fields, and allow the investigation of other business segments in short and long terms. However, the results presented are restricted to short-term payment capacity of the firms that met the standard requirements of IFRS (International Financial Reporting Standard), adopted in Brazil as of the second decade of the XXI century.

In addition to this introductory section, this article is composed by the following sections 2. Literature Review, which dialogues with the main contributions of the area's literature related to the topic; 3. Preliminary Considerations, which present the state of the art from where arises the proposed assessment model; 4. Methodology, which describes the purpose of the model's equations aimed at calculating the variables of the research's interest and which suggests an interpretation of the findings; 5. Data and Results Analysis, which presents and analyzes the answers of the tests obtained by the application of the model, and where the research question is answered; 6 . Conclusion, which summarizes the research findings as well as its main contributions; and References, where the bibliography that contributed to the literature and the present article is listed.

\section{Literature Review}

In this section, we discuss the studies produced by pieces of research on sustainability, in both a broad and 
restricted context. In the broad context, we bring into the discussion the studies addressing socioenvironmental aspects, whereas in the restricted context, the discussion encompasses studies related to aspects of liquidity management. Whatever the context is, we must consider interdependence, as one context affects the other, and because an entity' physical actions, which have an impact on the social, the ecological, the firm's management and on their liquidity, produce results that are disclosed in their financial statements.

\subsection{Sustainability in the Broad Context}

The discussion on sustainability requires the licit use of economic and production factors, like not degrading natural resources, respecting to workers' rights, not using slave work and practicing fair trade. Socially speaking, Belaggio (2012, p. 1) defines slave work as

"the status or condition of a person over whom any or all of the powers attaching to the right of ownership are exercised"

And economically speaking, McDonagh (2002) states that fair trade is "No universally accepted, authoritative definition of fair trade exists" although some organizations express this intention in the form declared by the Fair Trade Federation (1999, p. 5):

“'fair trade' means that trading partnerships are based on reciprocal benefits and mutual respect; that prices paid to producers reflect the work they do; that workers have the right to organize; that national health and safety, and wage laws are enforced; and that products are environmentally sustainable and conserve natural resources."

As argued by Dyllick and Hockerts (2002) an economically sustainable firm maintains, on a continuous basis, enough cash flow to guarantee liquidity at the same time that it produces an above-the-average persistent return to its shareholders. They also argue that an ecologically sustainable firm uses "only natural resources that are consumed at a rate below the natural reproduction or a rate below the development of replacements". Such a firm does "not causes emissions that accumulate in the environment at a rate beyond the natural system capacity to absorb and assimilate them, nor engage in activities that degrade the ecosystem's services". The authors' assertion is compatible and contemporary because, in fact, as consumers become more aware of their role in society, they also become more committed to their own and to future generations. With this commitment, consumers avoid buying goods that degrade nonrenewable resources, which entails insufficient liquidity for firms that produce such goods.

Koellner, Weber, Fenchel, and Scholz (2005) discuss the idea of sustainable investments in the market. They claim that both private and institutional investors complement financial considerations with social and ecological ones in order to assess sustainability, mainly by the growth of the so-called "green funds", which are managed according to the requirements of sustainability and social responsibility. The authors' contributions focus on the outline of basic principles and methods of classifications for sustainability, on the evaluation of the research processes in the fund management, as well as on the investigation of fund portfolios in terms of the composition and sustainability performance.

In a globalized context, Christofi, Christofi, and Sisaye (2012) investigated disclosure methods of sustainable actions and compare DJSI World and GRI-G3 sustainability guidelines and the "triple-bottom-line" (TBL), using samples from DJSI World Index firms and from the GRI-G3 membership list, in order to assess the indicators of sustainability performance. In their analyses, they found differences in the methods used by DJSI World and GRI-G3, which may lead to an inadequate management with systemic, economic and socioenvironmental consequences, harmful to citizens and consumers in general. Such a view have been shared by Pope, Annandale, and Morrison-Saunders (2004), when they state that there is a risk that sum of environmental, social and economic factors may be lower than the whole.

In a study that explores the role of the business community in promoting sustainable consumption, Michaelis (2003, p. 915) states that the firms, keeping themselves within the business conduct, assume that their contribution to sustainability resides in improving eco-efficiency. They observed that sustainable consumption demands broader changes that include the incentives that shape the actions of firms and of other agents, besides changes in the culture that underlines the market's expectations.

The combination of basic factors of sustainability generates what the literature calls financial synergy, as discussed by Copeland, Weston, and Shastri (2005, pp. 762-763). According to the authors, financial synergy occurs when the costs of domestic financing are lower than the costs of external financing. In this context, the firm produces positive net cash flows and acquires bargain capacity, which means buying at lower prices and still maintaining or increasing its q-ratio, which is the relationship between the firm's market value and the 
replacement costs of its assets.

\subsection{Sustainability in a Restricted Context}

In a general context, Richards and Laughlin (1980) analyze the literature's contribution to the firms' long-run working capital management, investments and financing policies. They observed that working capital management receives less attention than the others do and warned that such inattention to the process of liquidity management may render inefficiency due to adverse short-run occurrences. Their conclusions suggest that conducting only an examination of the conventional and static balance liquidity relations may hamper the firm's liquidity position, and in order to prevent this bias, it is necessary to incorporate activity indicators.

When investigating factors that influence liquidity management in Canadian firms, Gill and Mathur (2011) analyzed a sample of 164 firms listed in the Toronto Stock Exchange between 2008 and 2010. They argued that managers have the power to transform assets in their favor because they have implicit rights in the liquidity of assets and that any alteration in the liquidity would affect such rights. In their final remarks, they declared that corporate liquidity holding is influenced by the liquidity ratio, firm size, net working capital, near liquidity, short-term debt, investment, internationalization of firm, and industry.

With a strict view on the evaluation of cash flows, Lancaster, Stevens, and Jennings (1998) analyzed the relations between liquidity and competence-driven acknowledgement versus cash flow in static and dynamic aspects. In this analysis, they claim that they found evidence showing that the operations' cash flow is significantly related to the liquidity ratios and with the financial cycle, and that this relation has incremental and significant explanation provided by the revenue of each period. This statement effectively suggests the need for a thorough study on liquidity because the financial cycle, as the difference between the operating cycle and the average of payment terms, indicates a conceptual difference between nominal and effective payment capacities.

In a later study, Lancaster, Stevens, and Jennings (1999) empirically analyzed the firms' liquidity in a sample composed of several segments of different businesses, based on the cash flow conversion variables, extraordinary incomes, working capital and the operations' cash flow. They used static and dynamic liquidity measures (liquidity ratios and financial cycle). The authors believe that firms within the same business tend to have the same financial framework, whereas the significant variation in the financial framework occurs among business groups, but their findings show different impacts of these variables on dynamic and static liquidity for each industry and segment. The authors' emphasis on the financial cycle, to explain liquidity better, shows that there is a need for an indicator capable of reducing the asymmetry between nominal liquidity and effective liquidity. This indicator should combine the traditional liquidity indices with activity indicators.

Almeida, Campello, and Weisbach (2004) modeled the demand for liquidity to develop a new test of the effect of financial constraints on corporate policies. They establish the constraints conditions and show that "the effect of financial constraints is captured by the firm's propensity to save cash out of cash flows. They empirically estimated the cash flow's sensitivity of cash using samples of manufacturing companies within the period of 1971 and 2000, and declared that their findings provide a robust support to the theory.

In addition to the aforementioned studies, other studies seek to identify an optimal liquidity point, as in Gentry, Vaidyanathan and Lee (1990); Soenen (1993); Moss and Stine (1993); Stewart (1995), Farris II and Hutchison (2002); Gitman (2002, p. 112), among others. These studies analyze conceptual aspects, identify and quantify the components of the cash conversion or financial cycle, such as the operating cycle and the average purchases payment days. These contributions use the data that make up the working capital (current assets and current liabilities), stated in the financial statements of the companies, produced by the accounting department. However, even if the contributions are potentially relevant, there has not yet been an analytical demonstration that suggests a minimum point from which the sustainable liquidity.

\section{Preliminary Considerations}

In this section, we present the contributions found in the area's literature that support this study's propositions. Table 1 shows the concepts of financial and activity indicators. Their corresponding calculation methodology is found in the following equations 1 to 5 . 
Table 1. Relevant variables for the research present in traditional literature

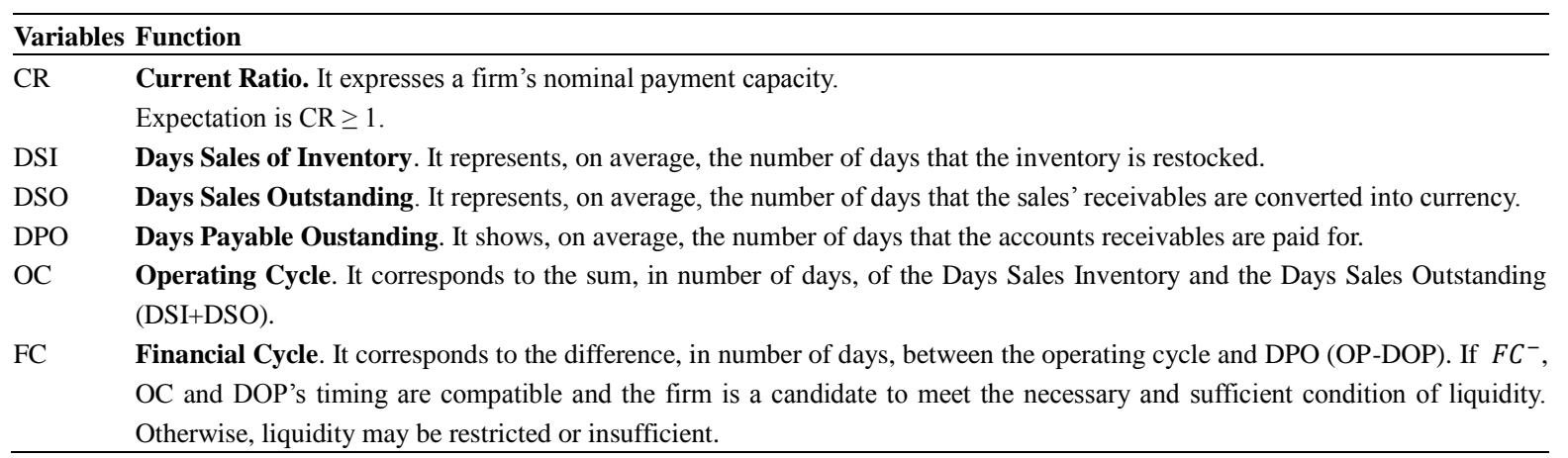

Source: Authors.

\subsection{Traditional Models}

Traditional models are composed by liquidity indicators and by activity indicators.

Among the liquidity indicators, the literatures states the Current Ratio (CR) as the indicator representing nominal payment capacity of a firm (j), given by the relation between the current assets (CA) and the current liabilities $(\mathrm{CL})$ of a firm in a given period of time (p), shown as:

$$
\mathrm{CR}_{\mathrm{j}, \mathrm{t}}=\mathrm{CA}_{\mathrm{j}, \mathrm{t}} * \mathrm{CL}_{\mathrm{j}, \mathrm{t}}^{-1} ; j=1, \ldots, n ; t=\text { period } ; C L>0
$$

With respect to the activity indicators, the chosen ones are those that represent the average timing of inventory turnovers, deadlines of payments and receipts, whose combination result in indicators of operating cycle and financial cycle, as shown in equations (1) and (5) to follow.

\section{(a) Days Sales Outstanding (DSO)}

DSO is the indicator that signals, on average, in how many day the account receivables of a sale are converted into cash. It is a relevant indicator in the composition of cash inflows.

$$
D S O=\frac{T * A R}{G R}
$$

where $\mathrm{T}$ stands for the time scale (days, for example); AR stands for the average balance of account receivables within time period T; and GR stands for the gross revenue of sales within time period T.

\section{(b) Days Sales of Inventory (DSI)}

DSI indicates, on average, in how many days the inventory is restocked, as defined by Equation (2). The inventory's turnover occurs via sales on credit, generating sales receivables and cash sales. In a manufacturing company, this indicator is significant for the operating cycle analysis.

$$
D S I=\frac{T * S I}{\operatorname{COGS}}
$$

where $\mathrm{T}$ stands for the period in time units (days, for example); SI stands for the average balance of the sales' inventory within period T; and COGS stands for the cost of goods sold within period T.

\section{(c) Days Payable Outstanding (DPO)}

DPO indicates in how many days, on average, a firm's invoices are paid, as seen in Equation (3). In financial management, it is expected that this indicator be greater than the operating cycle indicator.

$$
D P O=\frac{T * E A P}{C G S}
$$

where $\mathrm{T}$ stands for the period in time units (days, for example); EAP stands for the average balance of the ending accounts payable within period T; and GCS stands for gross cost of sales within period T.

\section{(d) Operating Cycle (OC)}

OC corresponds to the sum of the Days Sales Inventory and the Days Sales Outstanding, as shown by Equation (4). Developed like this, OC indicates the average time, in days, that it takes for a sale's product takes to enter the firm's inflow cash.

$$
O C=D S I+D S O
$$

\section{(e) Financial Cycle (FC)}

FC corresponds to the difference between the OC and the DPO. In a financially efficient and sustainable management, it is expected that the $\mathrm{FC}$ be, at most, equal to zero $(\mathrm{FC} \leq 0)$. In this condition, the FC suggests that 
the cash outflow required by the accounts payable occurs after the cash inflow from the operating cycle's components.

$$
F C=O C-D P O=D S O+D S I-D P O
$$

\subsection{Deterministic Method - Data Envelopment Analysis (DEA)}

DEA is a deterministic model used to evaluate efficiency. With the application of DEA, one can evaluate a DMU's (Decision Maker Unit) performance in comparison to another DMU (whether it is an administrative or an operating unit) that performs similar tasks. They can be differentiated by the amount of inputs consumed to produce a given good or a service, or by the amount of goods or services produced with the same amount of inputs (Charnes; Cooper; Rhodes, 1978; Banker; Charnes; Cooper, 1984). In this respect, DEA's approaches may be calculated with a focus on the constant returns to scale (CCR/CRS) and/or with a focus on the variable return to scale (BCC/VRS), as shown by Mello, Meza, Gomes, and Neto (2005). For these models, what is characterized as efficient is the maintenance of the volume of production with fewer inputs or a higher production with the same inputs (see Charnes, Cooper, \& Rhodes, 1978; and Banker, Charnes, \& Cooper, 1984; CCR and BCC models).

The literature shows that DEA is also applicable to an intangible good, which was used to evaluate the Greek financial system and European banks' efficiency and performance by Halkos and Salamouris (2004) and Beccali, Casu, and Girardone (2006) respectively, corroborating with results of Berger and Humphrey (1992).

\section{Methodology}

In this section, we formalize the analytical models of the ratios proposed by this research to assess the firm's financial efficiency and liquidity sustainability. The results produced are tested by using the positivist and deterministic methods, which are respectively, the test of significance via linear regression and the test of DEA efficiency. The inputs used to evaluate the ratios are those produced by the traditional literature as described in the previous section.

The coefficients that the present research introduces, denominated "financial efficiency ratio (FER)" and "liquidity sustainability ratio (LSR)", described in subsections 4.1 and 4.2 below, in average terms, can improve the explanatory power of liquidity, as they demonstrate and meet the requirements of financial synergy and sustainable liquidity, which the traditional indicators do not.

The results expected to be obtained by applying the models are fit to answer the question proposed as the research problem.

\subsection{Financial Efficiency Ratio (FER)}

By formalizing FER, we introduce the concept of a firm's financial efficiency in the period of time $\mathrm{T}$ as:

Definition:

A firm is financially efficient in a defined period of time $T$ if

$$
D P O \geq O C \text { or } D P O=0
$$

Thus, if $D P O$ is at least equal to $\mathrm{OC}$, this implies that the firm is financially balanced and is capable of paying off its obligations.

However, in order to assess a firm's financial efficiency in the period of time T, FER is assumed as:

$$
F E R= \begin{cases}(1+i)^{\frac{F C}{O C}} & \text { if } D P O \neq 0 \\ 1 & \text { if } D P O=0\end{cases}
$$

where $i$ is the inflation index (CPI, for example).

The analytical expression of FER is built exponentially to force results to always be greater than zero, substantiating the understanding that negative financial efficiency is meaningless.

With these assumptions, the necessary and sufficient condition to guarantee that there is financial efficiency is introduced.

Theorem:

The necessary and sufficient condition for a firm to be financially efficient is:

FER $\in(0,1]$

Proof:

[necessary condition]: if a firm is financially efficient, then 


$$
D P O=0 \text { or } D P O \geq O C \text {. }
$$

If $D P O=0$, then FER $=1$

Otherwise, $D P O \geq C O$, therefore $\frac{D P O}{O C} \geq 1 \Rightarrow 1-\frac{D P O}{O C} \leq 0$, thus FER $\in(0,1]$.

[sufficient condition]: if FER $\in(0,1]$, then FER $\in(0,1)$.

By definition, $F E R=(1+i)^{\frac{F C}{O C}}$. As $(1+\mathrm{i})>1$, then $\frac{F C}{O C}<0$

But $\frac{F C}{O C}=\frac{O C-D P O}{O C}=1-\frac{D P O}{O C}<0$, therefore $1<\frac{D P O}{O C}$. Thus, $O C<D P O$.

Othewise, FER $=1$. In this case, by the definition of FER, DPO $=0$ or $\frac{F C}{O C}=0$.

If $\frac{F C}{O C}=0$, then $D P O=O C$. Therefore $D P O=0$ or $O C=D P O$.

Then, by definition, the firm is financially efficient and this is the basic premise of financial synergy.

\subsection{Liquidity Sustainability Ratio (LSR)}

To test whether liquidity is sustainable, we introduce the liquidity sustainability ratio (LSR) and assesses the existence of financial synergy.

$$
L S R=\frac{\frac{C A}{C L}}{F E R}=\frac{C A}{C L} * \frac{1}{F E R}
$$

where CA stands for current assets in the period of time T; and CL stands for current liabilities in the period of time T;

Definition:

A firm's liquidity is sustainable in the period of time $T$ if:

$L S R \geq 1$, otherwise, liquidity is not sustainable.

The necessary and sufficient condition for liquidity is:

$C R \geq F E R$.

In this context, we introduce three situations that characterize liquidity sustainability status:

a) If $C R \geq 1 \geq F E R$, liquidity is strongly sustainable;

b) If $C R \geq F E R>1$ or $F E R \leq C R<1$, liquidity is weakly sustainable;

c) If LSR $<1$, liquidity is not sustainable.

The situation defined in "a" meets the requirements of financial synergy because it indicates that liquidity is sustainable.

\subsection{Data Envelopment Analysis (DEA)}

To run the DEA model, CR and FC are used as input variables to produce LSR as the output variable. The result given by the model is restricted to the sample firms, and may be different if more firms or other variables are added.

$$
\begin{gathered}
\text { Efficiency }\left(\text { Eff }_{0}\right)=\frac{\text { Production }}{\text { Input }} ; h_{0}=1 / E f f_{0} \\
\text { Max } h_{0} \\
\text { Efficiency Ratio }=1-h_{0}
\end{gathered}
$$

Where $\mathrm{Eff}_{0}$ is the efficiency of $\mathrm{DMU}_{0}$ under analysis; DMU is Decision Maker Unit.

The result of the model is presented in as a rank considering the combination of input variables, in average terms, for the periods considered.

\subsection{Linear Regression Theoretical Model}

The parametric model of hypothesis test is defined by the linear regression theoretical model demonstrated in Equation (8), which uses FC as a dependent variable (explained) and InvCR and OC as independent variables (explanatory). FC is used as a dependent variable because it conveys financial efficiency evidence as a necessary and sufficient condition to obtain liquidity status. InvCR and OC are used as independent variables because they convey, respectively, nominal payment capability and the activity ratio necessary to assess a firm's financial efficiency.

$$
F C_{j t}=\alpha+\beta_{1} I n v C R_{j t}+\beta_{2} O C_{j t}+\varepsilon_{j t}
$$

where $F C$ is financial cycle; $O C$ is operating cycle; InvCR is the inverse of current ratio; $\alpha$ is the constant term; 
$\beta$ is the angle coefficient; $j$ is the firm; $t$ is the time period; and $\varepsilon$ is the error term.

The sign for each beta coefficient $(\beta)$ indicates the positive or negative impact on financial efficiency of the variables InvCR and OC.

\section{Data and Results Analysis}

In this section, we analyze the combinations of the variables shown in Table 1, which make up a firm's liquidity status.

The primary data used to calculate the observations of each variable were analyzed with respect to the requirement of consistency and completion of each financial statement, by firm and year, according to the standard requirements of IFRS (International Financial Reporting Standard). Out of the total of manufacturing firms listed, those with financial statements containing data that were incomplete, inconsistent, and discontinued for a period of time were excluded. Thus, as a result of this selection criterion, only 37 firms had financial statements with validated data. Tests were run using the free statistical packages Gretl and DEA-solver.

\subsection{Liquidity Status of the Firms}

Using the data collected from the financial statements of the sample constituted of 37 firms in equations 1 to 7 , the following ratios were calculated: (a) nominal payment capability and activity (CR, DSI, DSO, DPO); (b) financial and operating cycle ratios (FC, OC); (c) financial efficiency ratio (FER); and (d) liquidity sustainability ratio (LSR). These ratios are shown in Table A of APPENDIX 2 and indicate that, from the sample of 37 firms, only six do not comply with the nominal liquidity requirement, with $\mathrm{CR}<1$; only two firms are financially efficient, with FC $<0$; and the liquidity status of 7 firms is not sustainable, with LSR $<1$. This evidence shows, preliminarily, that manufacturing firms in Brazil are not financially efficient.

APPENDIX 1 (Table C), composed of 592 observations, shows the traditional financial coefficients and those introduced by this survey, for each firm and year, calculated according to each equation of the model. APPENDIX 2 consists of Tables $\boldsymbol{A}$ and $\boldsymbol{B}$. Table $\boldsymbol{A}$ contains the same coefficients as Appendix 1, but only with the averages of each firm (37) for the entire period; Table $\boldsymbol{B}$ contains the test result calculated by the DEA, according to the indicators in Table $\boldsymbol{A}$.

Table 2 below shows the number of observations per year for each of the three liquidity status, as defined in the previous subsection 4.2. The observations by year and status were collected from Table C of APPENDIX 1, which shows ratios that were identified and calculated according to the objectives of this research.

Table 2. Liquidity sustainability status of 592 observations of 37 manufacturing firms in Brazil from 2000 to 2015 by number of observations

\begin{tabular}{|c|c|c|c|c|}
\hline Year & Not sustainable & Weakly Sustainable & Strongly sustainable & No. of firms \\
\hline 2000 & 8 & 29 & & 37 \\
\hline 2001 & 8 & 29 & & 37 \\
\hline 2002 & 10 & 27 & & 37 \\
\hline 2003 & 10 & 27 & & 37 \\
\hline 2004 & 9 & 28 & & 37 \\
\hline 2005 & 8 & 28 & 1 & 37 \\
\hline 2006 & 7 & 30 & & 37 \\
\hline 2007 & 8 & 29 & & 37 \\
\hline 2008 & 9 & 28 & & 37 \\
\hline 2009 & 5 & 32 & & 37 \\
\hline 2010 & 7 & 30 & & 37 \\
\hline 2011 & 8 & 29 & & 37 \\
\hline 2012 & 7 & 30 & & 37 \\
\hline 2013 & 8 & 29 & & 37 \\
\hline 2014 & 11 & 26 & & 37 \\
\hline 2015 & 9 & 28 & & 37 \\
\hline total & 132 & 459 & 1 & 592 \\
\hline
\end{tabular}

Strongly sustainable: firms that comply, simultaneously, with the necessary and sufficient condition for liquidity and for nominal liquidity; Weakly sustainable: firms that do not comply, simultaneously, with the necessary and sufficient condition for liquidity and for nominal liquidity; Not sustainable: firms with LSR $<1$. 
Table 2 shows that the combination of data from the variables CR and FER shape the liquidity status. In quantitative terms, the weakly sustainable status prevails with 459 out of 592 observations from the sample, which correspond to $77.53 \%$; there is a minimal presence of only one observation for the strongly sustainable status, corresponding to $0.17 \%$; and, lastly, for the not sustainable status, there are 132 observations, which correspond to $22.30 \%$. This distribution conveys, beforehand and based on the sample data, that manufacturing firms in Brazil resort to alternative funding sources to obtain liquidity, maybe because their financial cycle is greater than zero $\left(\mathrm{FC}^{+}\right)$, or because firms do not show financial efficiency, or yet because they do not comply with the nominal liquidity requirement. These results are compatible with those found by Gill and Mathur (2011) in terms of liquidity holding and type of activity, and are consistent with Richards and Laughlin (1980) observations that suggest that the current ratio should be combined with activity ratios for a proper representation of a firm's liquidity. In this way, the results of Table 2 do not confirm the existence of financial synergy.

\subsection{Deterministic Efficiency versus Financial Efficiency}

In this section, we evaluate the results obtained by applying the DEA model, in output oriented CCR and BCC approaches, using the answers in Table $\mathrm{C}$ of APPENDIX 1. The input variables used as indication of efficiency, scores(h), are $X=(C R, F C)$; and the output variable is $Y=(L S R) ; \mathrm{i}=(\mathrm{DMU})$ less efficient firm; $\mathrm{j}=(\mathrm{DMU})$ more efficient firm; $\mathrm{k}=$ combination $(\mathrm{i}, \mathrm{j}) ; \lambda=$ greater DMU productivity, according to the model demonstrated in subsection 3.3.

Each firm represents a DMU and the score, $h \in(0,1]$, conveys the efficiency produced by the combination of the input variables, (CR, FC), financial efficiency with nominal liquidity. This efficiency is the best combination of the two input variables in order to produce the liquidity status represented by LSR. So the score $h=1$ may correspond to any liquidity status produced by the synergy between the two input variables regardless of that being the strongly sustainable status.

The scores(h) rank shown in Table $\mathrm{C}$ of APPENDIX 1 conveys the best synergy that can be obtained by the variables FER and CR to produce LCR. DMUs E9 and E8 stand out in the CCR approach, and DMUs E9, E8, E6, E27 and E19 in the BCC approach reached the efficiency level. The BCC approach captures more deterministically efficient DMUs because it uses variable references $(\lambda)$, while CCR uses fixed references $(\lambda)$.

The efficiency scores obtained by DMUs E9 and E8 confirm the indication of financial efficiency shown by the same firms in Table A of APPENDIX 2, where the calculated FC is smaller than zero (FC). This identity confirms that DEA efficiency results are directly related to a firm's financial efficiency and not, necessarily, to the liquidity sustainability status.

On the one hand, DMUs E6, E27 and E19, ranked as deterministically efficient in the BCC approach, show the combination that produces the best synergy among the non-financially efficient firms. On the other hand, the non-efficiency indication $(h<1)$ of firms that comply with the nominal liquidity requirement is that each DMU could produce better synergy with the available input variables (CR, FC) and could improve financial efficiency and, consequently, obtain the strongly sustainable liquidity status.

DEA results also confirm that manufacturing firms in Brazil do not operate with financial efficiency or with liquidity sustainability.

\subsection{Descriptive Statistics}

Table 3 shows descriptive statistics of the five most relevant variables that form the liquidity status which represent the nature of the research. The estimators for the variables CR, FC, OC, FER and LSR are shown by the total of observations in the three liquidity status.

Table 3. Descriptive statistics of relevant variables in 592 observations in the sample of 37 manufacturing firms in Brazil from 2000 to 2015

\begin{tabular}{cccccccc}
\hline Estimators & Mean & Median & Std Dev & CV & Minimum & Maximum & Obs \\
\hline CR & 2.149 & 1.676 & 2.256 & 1.049 & 0.079 & 29.10 & 592 \\
FC & 175.619 & 119.938 & 364.469 & 2.075 & -3009.89 & 5412.44 & 592 \\
OC & 228.926 & 160.160 & 341.686 & 1.492 & 45.616 & 5350.33 & 592 \\
FER & 1.046 & 1.053 & 0.023 & 0.022 & 0.870 & 1.070 & 592 \\
LSR & 2.0 & 1.586 & 2.121 & 1.039 & 0.077 & 27.31 & 592 \\
\hline
\end{tabular}

$\mathrm{CR}=$ current ratio; $\mathrm{FC}=$ financial cycle; $\mathrm{OC}=$ operating cycle; FER = financial efficiency ratio; $\mathrm{LSR}=$ liquidity sustainability ratio. 
The statistical estimators for the 592 observations in the sample indicate, on average, that the liquidity status of the firms is, noteworthily, weakly sustainable, confirming previous evidence. This indication comes from CR > FER > 1, relative to the estimator for the mean, which is in accordance with the theory described in the previous subsections.

However, in spite of the liquidity status measured by LSR and the financial efficiency measured by FER, the distribution keeps close to the mean, with a minimum dispersion of 0,022 and a maximum of 2,075 standard deviations from the mean, with greater concentration around 1 , as shown by the coefficient of variation $(\mathrm{CV})$.

\subsection{Regression Results}

The data used to feed the linear regression functional model defined by Equation 8 were organized in a balanced panel and run by Generalized Least Squares (GLS). The dependent variable is the financial cycle (FC) and the independent variables are the operating cycle (OC) and the inverse of the current ratio (CR). CF indicates whether the firm is eligible for a financially efficient condition and its combination with the interest rate and nominal liquidity results in one of the three liquidity status.

The test result shown in Table 4 below is robust because, with $99 \%$ confidence, the autocorrelation in the residuals hypothesis is rejected, as shown by DW statistics $\left(\mathrm{dl}=1.748 ; \mathrm{d}=2.037 ; \mathrm{du}=1.789 ; \mathrm{d}_{\mathrm{u}}<\mathrm{d}<4-\mathrm{d}_{\mathrm{u}}\right)$, the adjusted R-squared shows that $73 \%$ of the result are explained by the model's independent variables, which suggests that the model is adequately adjusted.

However, when it comes to homoscedasticity, according to the White test (Hill, Judge, \& Griffiths, 2012, p. 278), the hypothesis was rejected. Notwithstanding the presence of homoscedasticity, as it is a characteristic of the sample, the rest of the Ordinary Least Squares (OLS) properties remain valid (Gujarati, 2006, p.318) and there is no multicollinearity as shown by the smaller than 10 FIV coefficient. Nevertheless, when using the corrected heteroscedasticity model, the coefficients become homoscedastic, as seen in part (b) of Table 4. This correction is shown by the change in the coefficients, standard error and t-statistic. With this correction, all the premises of the model remain valid.

Table 4. Results of the regression of FC against OC and the inverse of CR run by OLS and corrected heteroscedasticity (GLS) of the 592 annual observations of the sample of 37 manufacturing firms in Brazil from 2000 to 2015

\begin{tabular}{|c|c|c|c|c|c|c|c|c|}
\hline \multirow[t]{2}{*}{ Estimator } & \multicolumn{4}{|l|}{ (a) OLS } & \multicolumn{4}{|c|}{ (b) Corrected heteroscedasticity(GLS) } \\
\hline & Coeff. & Std error & T-statistic & p-value & Coeff. & Std error & T-statistic & p-value \\
\hline Const & $-9,467$ & 10,517 & $-0,900$ & 0,368 & -12.899 & 2.900 & -4.448 & $* * *$ \\
\hline InvCR & $-24,048$ & 5,152 & $-4,667$ & $* * *$ & -26.455 & 2.480 & -10.67 & $* * *$ \\
\hline $\mathrm{OC}$ & 0,911 & 0,023 & 39,700 & $* * *$ & 0.956 & 0.0132 & 72.28 & $* * *$ \\
\hline R-squared & 0,729 & \multicolumn{2}{|c|}{ White coeff:Est-LM } & 47,595 & & & & \\
\hline Adjusted R-squared & 0,728 & \multicolumn{2}{|c|}{ Durbin-Watson } & 2,037 & & & & \\
\hline \multirow[t]{2}{*}{ FIV: } & InvCR & 1,004 & $\mathrm{~F}(2,589)$ & 790,235 & & & & \\
\hline & $\mathrm{OC}$ & 1,004 & P-value(F) & 0 & & & & \\
\hline
\end{tabular}

$\mathrm{OC}$ is operating cycle; and InvCR is inverse current ratio.

The results shown by the OLS functional model, with heteroscedasticity corrected by GLS, keep the same signal of the original regression, with the operating cycle and the nominal liquidity directly associated with the financial cycle, but the estimators were modified because of the correction, in order to have the best non-biased estimators. These associations suggest that, when CR and FC grow by 1, FC grows by 26 and 0.9 , respectively, with the transformation of the OLS model into GLS.

In addition to this robust evidence, the unit root and non-stationarity test and cointegration were applied according to Dickey-Fuller, with the variables in level I $(0)$ and first difference I(1). The results of the test show that the measured statistic $(\tau)$ is superior to the critical statistic $(\tau)$ suggesting the rejection of the null hypothesis of unit root. The test was taken with and without drift and constant.

These results are in accordance with those found by Richards and Laughlin (1980) and Almeida, Campello and Weisbach (2004), because CR, as nominal payment capability, is corrected by the time frame of the efficiency ratio produced by the activity ratios.

The results of the test are also consistent with the theory because OC being the sum of the average maturities of 
the assets to be converted into cash, the increase of one in these periods, in average terms, impacts reduction of the $\mathrm{FC}$, as shown by the coefficient 0,95 which is less than 1 .

\section{Conclusion}

The research presented in this article presented theoretically and evaluated empirically the concepts of financial efficiency, by means of FER, and of liquidity sustainability, by means of LSR. It evolved from the analysis of traditional liquidity, with the combination of activity indicators represented by nominal liquidity and activity ratios built from financial statements data from a sample of 37 manufacturing firms in Brazil from 2000 to 2015.

The results suggest that the combination of financial efficiency and nominal liquidity is a robust indication for the liquidity status in which manufacturing firms operate. This conclusion is unequivocally robust as it is supported by evidence from the tests shown below:

(a) The evidence shown in Table 2 indicates that more than 3/4 of the manufacturing firms in Brazil operate with weakly sustainable liquidity; more than $1 / 5$ with not sustainable liquidity; and less than $0.2 \%$ with strongly sustainable liquidity;

(b) Efficiency evaluated by DEA confirms that the liquidity sustainability status is influenced, chiefly, by financial efficiency;

(c) Tests evaluated by the multiple linear regression functional model confirm that operating cycle and nominal liquidity are directly associated to financial efficiency, and both impact liquidity sustainability. The test results are presented in line with the theory when they suggest that an increase of OC generates a reduction of FC. FER and LSR models presented in this article are adequate to measure a firm's liquidity sustainability and solvency, and they fill the gap in the literature.

The evidence shown is robust enough to promote the discussion that manufacturing firms in Brazil operate neither with financial efficiency, nor with sustainable liquidity, nor produce financial synergy. These findings suggest that there is a relevant field of research to be explored in other business segments.

Finally, we expect that the findings of this research, which focus on financial efficiency and liquidity stability, contribute with the literature, academic activities and market professionals, helping managers and researchers obtain better empirical results..

\section{References}

Almeida, H., Campello, M., \& Weisbach, M. (2004). The cash flow sensitivity of cash. The Journal of Finance, LIX(4). https://doi.org/10.1111/j.1540-6261.2004.00679.x

Banker, R. D., Charnes, A., \& Cooper, W. W. (1984). Some models for estimating technical scale inefficiencies in data envelopment analysis. Management Science, 30(9), 1078-109. https://doi.org/10.1287/mnsc.30.9.1078

Beccalli, E., Casu, B., \& Girardone, C. (2006). Efficiency and stock performance in european banking. Journal of Business Finance \& Accounting, 33(1\& 2), 245-262. https://doi.org/10.1111/j.1468-5957.2006.01362.x

Berger, A. N., \& Humphrey, D. B. (1992). Megamergers in banking and the use of cost efficiency as an antitrust defence. Antitrust Bulletin, 33, 541-600. https://doi.org/10.1177/0003603X9203700302

Charnes, A., Cooper, W. W., \& Rhodes, E. (1978). Measuring the efficiency of decision-making units. European Journal of Operational Research, 2, 429-444. https://doi.org/10.1016/0377-2217(78)90138-8

Christofi, A., Christofi, P., \& Sisaye, S. (2012). Corporate sustainability: Historical development and reporting practices. Management Research Review, 35(2), 157-172. https://doi.org/10.1108/01409171211195170

Copeland, T. E., Weston, J. F., \& Shastri, K. (2005). Financial theory and corporate policy (4th ed.). Boston: Pearson.

Dyllick, T., \& Hockerts, K. (2002). Beyond the business case for corporate sustainability. Business Strategy and the Environment, 11(2), 130-141. https://doi.org/10.1002/bse.323

Farris, II, Theodore, M., \& Hutchison, P. D. (2002). Cash-to-Cash: The new supply chain management metric. International Journal of Physical Distribution \& Logistics Management, 32(4), 288-298. https://doi.org/10.1108/09600030210430651

Gentry, J. A., Vaidyanathan, R., \& Lee, H. W. (1990). A weighted cash conversion cycle. Finance Management, 19(1), 90-100. https://doi.org/10.2307/3666040

Gill, A., \& Mathur, N. (2011). Factors that influence corporate liquidity holdings in Canada. Journal of Applied 
Finance \& Banking, 1(2), 133-153.

Gitman, L. J. (2002). Principles of managerial finance (7th ed.). São Paula: Harbra.

Gujarati, D. (2006). Econometria básica (4th ed.). Rio de Janeiro: Elsevier/Campus.

Halkos, G. E., \& Salamouris, D. S. (2004). Efficiency measurement of the Greek commercial banks with the use of financial ratios: A data envelopment analysis appDAch. Management Accounting Research, 15, 201-224. https://doi.org/10.1016/j.mar.2004.02.001

Hill, R. C., Judge, G. G., \& Griffiths, W. F. (2012). Econometria (3rd ed.). São Paulo: Saraiva.

IASB. (1997). International Accounting Standards Committee. IFRS.

Koellner, T., Weber, O., Fenchel, M., \& Scholz, R. (2005). Principles for sustainability rating of investment funds. Bus. Strat. Env., (14), 54-70. https://doi.org/10.1002/bse.423

Lancaster, C., Stevens, J. L., \& Jennings, J. A. (1998). Corporate liquidity and the significance of earnings versus cash flow. The Journal of applied Business Research, 14(4), 27-38. https://doi.org/10.19030/jabr.v14i4.5649

Lancaster, C., Stevens, J. L., \& Jennings, J. A.(1999). Corporate liquidity and the significance or earnings versus cash flow: An examination of industry effects. The Journal of Applied Business Research, 15(3), 37-46. https://doi.org/10.19030/jabr.v15i3.5669

Melo, J. C. C. B. S., Meza, L. A., Gomes, E. B., \& Neto, L. B. (2015). Curso de análise de envoltória de dados. In XXXVII simpósio brasileiro de pesquisa operacional (SBPO), Gramado, 2005. Retrieved from http://www.uff.br/decisao/sbpo2005_curso.pdf

Michaelis, L. (2003). The role of business in sustainable consumption. Journal of Cleaner Production, 11, 915-921. https://doi.org/10.1016/S0959-6526(02)00160-9

Moss, J. D., \& Stine, B. (1993). Cash conversion cycle and firm size: a study of retail firms. Managerial Finance, 19(8), 25-35. https://doi.org/10.1108/eb013739

Richards, V. D., \& Laughlin, E. J. (1980). A cash conversion cycle approach to liquidity analysis. Financial Management, 9(1), 32-38. https://doi.org/10.2307/3665310

Soenen, L. A. (1993). Cash conversion cycle and corporate profitability. Journal of Cash Management, 13(4), 53-58.

Stewart, G. (1995). Supply chain performance benchmarking study reveals keys to supply chain excellence. Logistics Information Management, 8(2), 38-45. https://doi.org/10.1108/09576059510085000

\section{Copyrights}

Copyright for this article is retained by the author(s), with first publication rights granted to the journal.

This is an open-access article distributed under the terms and conditions of the Creative Commons Attribution license (http://creativecommons.org/licenses/by/4.0/). 